\title{
La industria editorial y el libre comercio
}

\author{
Enrique E. Sánchez Ruiz*
}

Este escrito es parte de la investigación más amplia que estamos desarrollando, que comenzó cuando México suscribió el Tratado de Libre Comercio de América del Norte (TLCAN). ${ }^{1}$ Desde entonces nos interesó continuar haciendo el balance continuo de las repercusiones de esta generalización del "libre comercio" sobre las industrias culturales mexicanas; de la forma de inserción actual de México en la globalización y de sus implicaciones y repercusiones sociales, culturales, políticas y económicas.

Iniciaremos con una breve contextualización conceptual e histórica, para luego describir las tendencias más recientes de la industria editorial mexicana en el seno del "libre comercio globalizador" y terminar con algunas propuestas. Finalmente, la gran interrogante consiste en si vamos a considerar los libros, las películas, la música, etc., como simples mercancías que deban ser dejadas al arbitrio de las "leyes del mercado", o si se les deba considerar formas de expresión cultural, artística, identitaria, que puedan y deban recibir alicientes para su desarrollo a partir de políticas públicas de apoyo y relativa protección en el ámbito nacional.

\section{Dialéctica de la mundialización.}

La llamada globalización es la etapa actual del largo desarrollo histórico del capitalismo. Se caracteriza porque el mundo contemporáneo se encuentra profusamente interconectado por enmarañadas redes y múltiples flujos dę comercio, de transacciones financieras, de información y cultura. ${ }^{2}$ Es también un proceso de articulación desigual, asimétrica a la que la mayor parte de las historias nacionales y los Estados nacionales se insertan diferencialmente. Un factor contribuyente al reinado de tales urdimbres ha sido el vertigi-

* Univeridad de Guadalajara

'En otros países de Latinoamérica le llaman por sus siglas en inglés: NAFTA. Los mexicanos estamos acostumbrados a denominarlo TLC, o TLCAN.

Incluida, aunque en menor medida, la "alta cultura"; en mucho mayor extensión, fluyen planetariamente los productos de las llamadas industrias culturales. 
noso florecimiento de las avanzadas tecnologías de información y comunicación, base fundamental de la "economía informacional", cimiento a su vez de la "sociedad red". Lo más sobresaliente de tales desarrollos tecnológicos recientes ha sido el proceso de convergencia de las telecomunicaciones (el teléfono, la comunicación vía satélite), con las tecnologías de información (las computadoras y todos sus periféricos, que han posibilitado constituir grandes redes, como la Internet), y con las industrias culturales, potenciadas enormemente por la digitalización. ${ }^{4}$ Así, por ejemplo a la Internet se le ha dado en llamar la "autopista de la información"; pero de igual forma se le podría denominar también "autopista de la diversión"," e incluso "autopista de la educación", pues todos esos usos se le dan ya intensivamente a la "red de redes". ${ }^{6}$ Esta nueva configuración histórica llamada "sociedad de la información" o "del conocimiento" se mueve en virtud de un motor central que habita en su esencia misma: es el nuevo carácter del capitalismo, metamorfoseado en "cibercapitalismo". ' La convergencia tecnológica ha venido de la mano con nuevas integraciones corporativas horizontales y verticales entre empresas que antes no tenían vinculaciones. Es decir, han convergido empresas de telecomunicaciones (telefónicas, por ejemplo) y compañías del sector informático, con firmas del área del entretenimiento, en particular de medios audiovisuales (las fusiones del tipo AOL-Time-Warner). Las grandes empresas editoras de libros y revistas a escala planetaria forman parte de estos desarrollos de alta concentración. Pero los procesos de integración vertical y horizontal, y de diversificación de los grandes conglomerados multimedia de hecho comenzaron hace varios decenios. Al parecer, la tendencia hacia la concentración de los capitales, presente en la convergencia corporativa, sigue contradiciendo al pensamiento liberal que supone la competencia como base y esencia de la libertad en el mercado.

${ }^{3}$ Castells, Manuel (1999), La era de la información. Economía, sociedad y cultura. Vol. I: La sociedad red, México: Siglo XXI.

'Sánchez Ruiz, Enrique E. (2000) "Globalización y convergencia: Retos para las industrias culturales latinoamericanas", en Revista Universidad de Guadalajara, Núm. 20, Abril.

"Tremblay, Gaëtan (1995) "Las autopistas de la diversión en Canadá", en Telos, Madrid, Núm. 41, Mar.-May., 1995.

Sánchez Ruiz, E. (2000) "Globalización y convergencia: Retos para las industrias culturales latinoamericanas", op. cit.

${ }^{7}$ Mosco, Vincent y Dan Schiller (2001) Continental Order? Integrating North America for Cybercapitalism. Lanham: Rowman \& Littlefield. 
La forma de incorporación de los países a este proceso histórico contemporáneo multidimensional es función de muchos factores, de los cuales hay uno fundamental: el grado de adelanto económico, que se traduce a su vez en mayor o menor "poder de mercado" en la arena económica mundial. Así, esta nueva urdimbre planetaria no es horizontal y equitativa, sino asimétrica, jerárquica y su configuración histórica responde a la distribución del poder a escala global, tanto en términos económicos como militares y políticos.

\section{"Integración latinoamericana" y libre comercio}

Desde el tiempo de las guerras de independencia ha existido el sueño de una integración de los pueblos latinoamericanos, los cuales tienen muchos aspectos culturales en común, como el lenguaje (por lo menos, los de habla hispana, aunque el portugués no es demasiado diferente del castellano), la religión dominante, algún grado de mestizaje y herencia indígena (subordinada históricamente por criollos y mestizos), además de luchas comunes, etc. Sin embargo, los intentos formales de integración y de articulación en lo económico, lo político y lo cultural entre países latinoamericanos, que hasta la fecha ha habido, han arrojado resultados poco o nada satisfactorios. ${ }^{9}$ En todo caso, el significado de la posible integración estaría cambiando en la actualidad, como lo comenta Roncagliolo:

En otro texto, que sirve de antecedente a éste (Roncagliolo, 1996), ${ }^{10}$ me he referido al significado equívoco del sintagma "integración latinoamericana": traté de destacar ahí cómo la palabra integración ha mudado de signo, pues antes portaba la connotación sindical y defensiva de unidad entre países pobres para hacer frente a los poderosos (un "integrar-nos" latinoamericanista), mientras que ahora, pese a Bolívar, Martí y tantos otros, apela, más bien, a los afanes de incorporación a

${ }^{8}$ Sánchez Ruiz, op. cit; ver Fossaert, Robert (1994) "El mundo en el Siglo XXI. Una teoría de los sistemas mundiales". México: Siglo XXI; González Casanova, P. y J. Saxe-Fernández (1996) "El mundo actual: Situación y Perspectivas". México: UNAM/Siglo XXI.

Un muy interesante recuento, con énfasis en aspectos mediáticos, está en: Roncagliolo, Rafael (1996) "La integración audiovisual en América Latina: Estados, empresas y productores independientes", en N. García Canclini (coord.) Culturas en Globalización. América Latina - Europa - Estados Unidos: Libre Comercio e Integración. Caracas: Editorial Nucva Sociedad.

${ }^{10}$. Se trata del texto mencionado en la nota anterior. 
uno de los bloques de la economía global (un "integrar-se" panamericanista). ${ }^{11}$

En el caso de la industria cultural, la "integración latinoamericana" parece seguir en la actualidad un trayecto "panamericanista" como lo describe Roncagliolo, pero no a partir de políticas públicas, sino de la lógica del mercado transnacional. Por ejemplo, así como la ciudad de México fue en los años cuarenta y cincuenta un centro-no el único pero sí el principal-, al que confluían cantantes, músicos y actores de toda América Latina, para hacerse conocer en el propio subcontinente, hoy en día hay un movimiento de desplazamiento de tal tipo de centralidad hacia Miami, donde coinciden tanto las personas (el "talento"), como los capitales, lo que incluye tanto los grandes capitales transnacionales, como los latinoamericanos mismos; ${ }^{12}$ por ejemplo, entre otros, el Grupo Cisneros de Venezuela ha mudado sus oficinas centrales de Caracas a Miami. Todo esto lleva a un estudioso estadounidense a afirmar que: "Para la industria de la música, como para la audiovisual, Miami es el eje de la integración latinoamericana". Sin embargo, las cosas no son tan simples: en el caso de la industria editorial latinoamericana, un actor recientementge fortalecido son las editoriales españolas, a su vez fuertemente articuladas con grandes consorcios transnacionales europeos. Algunos sectores como éste seguirían una ruta de "integración iberoamericana".

1 Roncagliolo, Rafael (1999) "Las industrias culturales en la videosfera latinoamericana", en N. García Canclini y C.J. Moneta (coords.) Las Industrias Culturales en la Integración Latinoamericana. México: Grijalbo/UNESCO/ SELA, p. 65.

Strover, Sharon (1998) "Spatialization and international communication industries: The case of Miami", en The Public, Vol. 5, Núm. 4; S. Strover et al (1999) "Transnationalism in spaces and places: Global media industries in Latin America", ponencia presentada en "NAFTA/Mercosur Conference", Univertity of Texas at Austin, Junio 1-3.

${ }^{13}$ Yudice, George (1999) "La industria de la música en la integración América Latina-Estados Unidos", en N. García Canclini y C.J. Moneta (coords.) Las industrias culturales en la integración latinoamericana, México: UNESCO/ Grijalbo/SELA., p. 213.

${ }^{14}$ Alatriste, Sealtiel (1999) "El mercado editorial en lengua española", en N. García Canclini y C.J. Moneta (coords.) Las industrias culturales en la integración latinoamericana, México: UNESCO/Grijalbo/SELA 
A pesar de que entre algunas de las narraciones o imaginarios de la globalización, se encuentra el relato de que las naciones y los estados nacionales "ya no existen", o en una versión más axiológica, que "ya no deberían existir", de hecho las naciones siguen constituyendo "comunidades imaginarias" siendo actores importantes en el escenario mundial, internacional. Esto, aún en el seno de las nuevas configuraciones regionales, como la propia Unión Europea, el TLCAN o el Mercosur. Las políticas públicas, entonces, resurgen como opción-quizás no la única, pero una entre un abanico realista de opciones - para orientar el rumbo histórico, frente al fundamentalismo del mercado y al fatalismo totalitario de la mundialización. Aclaremos que, si habla uno de políticas públicas, no necesariamente las opone uno total y radicalmente al mercado. Es decir, no niega uno la posible eficiencia relativa, en algunos casos, de la interacción entre la oferta y la demanda (las "fuerzas del mercado"). No partimos aquí de una concepción simplista y maniquea, sino más bien compleja, multidimensional y cambiante.

Como el Acuerdo de Libre Comercio de las Américas no existe todavía, revisemos algunos aspectos del Tratado de Libre Comercio de Norteamérica, enfocando en posibles repercusiones sobre la industria editorial mexicana, para imaginarnos: ¿qué ocurrirá con el proceso de "integración panamericana"?.

\section{TLCAN: Articulación asimétrica en norteamérica.}

La articulación desigual entre los socios del TLCAN se encuentra claramente en la siguiente descripción del Sistema Económico Latinoamericano (Sela):

La Zona de Libre Comercio de América del Norte está integrada por Canadá, Estados Unidos de América y México. Incluye a la economía más grande del mundo, la de EE.UU., lo que la

${ }_{15}^{15}$ García Canclini, Néstor (1999) La Globalización Imaginada, op cit.

${ }^{16}$ Anderson, Benedict (1991) Imagined Communities. Reflections on the Origin and Spread of Nationalism, Londres: Verso.

17 . Lind, Michael (2001) "Las bondades de la nación", en Este País, Núm. 124, Julio; Smith, Anthony D. (2000) Nacionalismo y Modernidad. Madrid: Istmo; Giddens, Anthony (1999) Un mundo desbocado. Los efectos de la globalización en nuestras vidas. Madrid: Taurus.

${ }^{18}$ Ver: Sánchez Ruiz, Enrique E. (2000) "Industrias culturales y globalización. Un enfoque histórico estructural”, en G. Orozco (coord.) Lo viejo y lo nuevo. Investigar la comunicación en el Siglo XXI. Madrid: Ediciones de la Torre. 
convierte, por la magnitud de su mercado, en un bloque comercial de alcance mundial.

Este hecho origina además diferencias dentro del propio espacio económico. El PIB de los Estados Unidos de América (US\$ 8,230 miles de millones para 1998) es casi catorce veces mayor que el de Canadá (US\$ 580 mil millones) y más de veinte veces mayor que el de México (US\$ 393 mill millones). Las diferencias de grado de desarrollo también son notables. Mientras el PNB per cápita de Estados Unidos es de US\$29,240 (1998) y el de Canadá de US\$19,170, el de México alcanzaba a US\$ 3,840. Otra característica del TLCAN es que agrupa a países que mantenían un alto nivel de intercambio antes de suscribir la asociación formal a través del Tratado.

(...) Su poblacion representa un $50.5 \%$ y su territorio un $53.6 \%$ del total del hemisferio occidental. Su Producto Interno Bruto un $88.2 \%$ del hemisférico de acuerdo a cifras de $1999 .{ }^{19}$

El comercio entre los tres signatarios del TLCAN era ya muy intenso mucho antes de comenzarse a negociar el tratado. De hecho, Estados Unidos era ya el principal socio comercial tanto de Canadá como de México, aunque éstos dos tenían relaciones comerciales muy marginales entre sí. El TLC intensificó aun más los vínculos, como se puede observar en el Cuadro 1.

\section{Cuadro 1. TLCAN}

Exportaciones totales e intrarregionales

(En miles de millones de dólares, fob y porcentajes)

\begin{tabular}{|c|c|c|c|c|c|c|c|}
\hline & 1990 & 1991 & 1992 & 1993 & 1994 & 1995 & $\begin{array}{lll}1996 & 1997 & 1998\end{array}$ \\
\hline $\begin{array}{l}\text { Exp } \\
\text { totales }\end{array}$ & 561.1 & 591.4 & 627.9 & 661.7 & 738.5 & 856.6 & 919.9999 .4996 .9 \\
\hline $\begin{array}{l}\text { Exp } \\
\text { intra } \\
\text { TLCAN }\end{array}$ & 240.5 & 249.4 & 273.4 & 301.3 & 352.0 & 395.5 & 437.5484 .5510 .8 \\
\hline $\begin{array}{l}\% \exp \\
\text { TLCAN/ } \\
\text { Total }\end{array}$ & 42.9 & 42.2 & 43.6 & 45.5 & 47.7 & 46.2 & $\begin{array}{lll}47.6 & 48.5 & 51.2\end{array}$ \\
\hline
\end{tabular}

Fuente: BID Integración y Comercio en América. Agosto y Diciembre 1998. ${ }^{20}$

${ }^{19}$. http://www,lanic.utexas.edu/ sela/AA2K1/ESP/docs/Integra/SPDi5-01/ spdi5-01-22.htm (bajado el 06/1 1/2002), en Guía de la Integración de América Latina y el Caribe 2002. Caracas, Sistema Económico Latinoamericano. Libro electrónico. Secretaría Permanente del SELA. Septiembre 2002. La entrada al libro electrónico estaba en:

(http://lanic.utexas.edu/ scla/AA2K/ES/books/integra/default2.htm).

${ }^{20}$ Tomado de SELA, Ibid. 
Efectivamente, el cuadro muestra que hubo un incremento substancial de la proporción de las exportaciones totales realizadas al interior de la región (del $43 \%$ en 1990, al $51 \%$ en 1998). Las evaluaciones sobre el TLC varían, según los aspectos en los que se ponga énfasis. Por ejemplo, no hay duda de que la integración comercial dinamizó las exportaciones y las inversiones en los tres países. ${ }^{21}$ Pero si se tiene en cuenta la generalización de los beneficios del libre comercio entre la población, resulta que, al favorecer principalmente al sector exportador, la apertura "ha agravado la polarización de la economía mexicana (...) Mientras que el ya mencionado y relativamente pequeño segmento exportador de la economía mexicana ha crecido en forma importante, el resto de la economía, y en especial las empresas de menor tamaño, han encontrado limitaciones para integrarse en este modelo de crecimiento". 22 En la medida en que se dinamizaron ciertos sectores y otros no, una evaluación encuentra que el impacto del TLCAN para los trabajadores de los tres países no ha sido satisfactorio, sino en el mejor de los casos, desigual. ${ }^{23}$ En Estados Unidos "más de 360,000 trabajadores han accedido a un programa de conversión de la mano de obra, debido a que sus empleadores decidieron trasladar la producción a México o a Canadá o que habían sido afectados por la competencia proveniente de ambos países". ${ }^{24}$ En lo que se refiere a México, es claro que la liberalización comercial incrementó la demanda por mano de obra calificada y en consecuencia aumentó la desigualdad en los salarios. ${ }^{25}$ A pesar de que la productividad del trabajo se incrementó en un $47.7 \%$, el valor del salario real en las manufacturas disminuyó un $20.6 \%$. Obviamente, un aspecto que ha recibido grandes críticas y preocupaciones, desde antes de la firma del Tratado, ha sido el de la

${ }^{2 l}$ Dussel Peters, Enrique (2000) El Tratado de Libre Comercio de Norteamérica y el Desempeño de la Economía Mexicana. Naciones Unidas, Comisión Económica para América Latina y el Caribe - CEPAL, Sede Subregional, México, D.F.

${ }^{22}$. Ibid, p. 86.

${ }^{23}$ NAFTA at Seven. Its Impact on Workers in All Three Nations. Washington: Economic Policy Institute Briefing Paper.

${ }^{24}$ Anderson, Sarah (2001) "Seven years under NAFTA". Washington, Institute for Policy Studies, Agosto, p. 5 ..

${ }^{25}$ Robertson, Raymond ( 2000) "Trade liberalisation and wage inequality: Lessons from the Mexican experience", en The World Economy (The Americas Edition 2000), Vol. 23, Núm. 6, Junio.

${ }^{26}$ Anderson, Sarah, op cit. 
soberanía, en particular de Canadá y de México, en función de la mayor articulación asimétrica con la economía más poderosa del mundo. ${ }^{27}$ Por ejemplo, para el caso mexicano, un informe de la Comisión Económica para América Latina y el Caribe (CEPAL) indica que:

En realidad, la creciente vinculación de México al mercado internacional equivale a una mayor integración de su economía al bloque de América del Norte, en particular los Estados Unidos. ... Entre 1990 y 1998, la importancia de América del Norte en el comercio mexicano total aumentó de $69 \%$ a $82 \%$, y más de dos tercios del acervo de IED en México tuvieron su origen en Estados Unidos y Canadá ${ }^{28}$

De hecho, esos "dos tercios" se traducen en $60 \%$ de Estados Unidos y $2.7 \%$ de Canadá. ${ }^{29}$ A pesar de que durante la administración de Ernesto Zedillo se firmaron acuerdos de libre comercio con casi una treintena de países, ${ }^{30}$ en realidad ha sido uno, el TLCAN, el que ha funcionado principalmente, vinculando de manera cada vez más estrecha a la economía mexicana con la estadounidense y, en menor medida, pero también, con la canadiense.

Los problemas de una articulación tan cercana y asimétrica se observaron durante años recientes, cuando a raíz del decrecimiento de la economía estadounidense, en México se cayó en una recesión que significó la pérdida de miles de empleos, en particular los ligados con las empresas exportadoras o con las maquiladoras de alta

${ }^{27}$ Aunque también se incluyen preocupaciones de índole política, militar y por supuesto culturales. Ver por ejemplo: Thompson, John H. y Stephen J. Randall (1994) Canada and the United States: Ambivalent Allies. Athens y Londres: The University of Georgia Press; Saxe-Fernandez, John (1998) "Redefinición de vínculos con Estados Unidos", en Luis González Souza (coord.) Reconstruir la Soberanía. México en la Globalización. México: La Jornada Ediciones / Instituto de Estudios de la Revolución Democrática.

${ }^{28}$ CEPAL (2000).. La inversión Extranjera en América Latina y el Caribe. Informe 1999. Santiago de Chile: Naciones Unidas, Comisión Económica para América Latina y el Caribe, p. 104.

${ }^{29}$ Ibidem.

30 "El Señor de los tratados", Expansión, Año XXXI, Núm. 792, Junio 7 , 2000. 
tecnología que, o cerraron, o disminuyeron enormemente su planta laboral. Finalmente, es claro que entre 1994 y 1998 hubo un aumento de la pobreza en México: de un $50.9 \%$ de la población al $58.4 \%$ que vive en la pobreza (en la extrema pobreza, del $21.5 \%$ al $27.2 \%$ ). ${ }^{32}$ Quizás no se pueda atribuír un lazo causal directo al TLCAN con el incremento de la pobreza y la desigualdad en México, pero sí claramente se explica por el modelo de desarrollo, llamado "neoliberal", que impulsa acoplamientos comerciales como el mismo TLCAN. Si no fuese porque ya muchos "sepultaron" la "teoría de la dependencia", se podría pensar que algunos aspectos de la misma todavía se seguirían aplicando a la articulación México-Estados Unidos.

La nueva etapa de desarrollo del capitalismo, en general, parece haber producido la mayor desigualdad histórica entre los países del mundo. ${ }^{35}$ La inequidad mundial en riqueza y en el acceso de la población a los beneficios del progreso se refleja en una desigualdad correspondiente en el desarrollo de las industrias culturales y en el acceso diferencial de los ciudadanos a estas fuentes de entretenimiento, información y educación. Así, por ejemplo una encuesta reciente de la UNESCO sobre las industrias cinematográficas nacionales, muestra que la capacidad de producción cinematográfica tiene una alta

31

"México, atado a la desaceleración económica de E.U. Empresas exportadoras, las más afectadas", El Financiero, 23 de febrero de 2001, p.8, sec. "Finanzas". Este comentario se refiere a la situación anterior al ataque terrorista del 11 de septiembre de 2001, que tendría consecuencias directas e indirectas en todas las economías nacionales del mundo.

${ }^{32}$ Anderson, Sarah, op cit. Variables como el índice de pobreza no pueden ser atribuídas causal y directamente al TLCAN, pero por lo menos se puede sugerir que el no mejoramiento de la situación en México puede relacionarse con el modelo que propició la firma e instrumentación del Tratado.

${ }^{33}$ Salama, Pierre (1999) Medida y Desmesura de la Pobreza. Guadalajara: Universidad de Guadalajara (Manuscrito inédito); Atkinson, Anthony B. (1999) Is rising inequality inevitable? A critique of the transatlantic consensus". Helsinski: United Nations University, WIDER Anual Lectures, Núm. 3.

${ }^{34}$ Lo interesante es encontrar, en documentos del gobierno estadounidense, análisis que aún intentan "poner a prueba" algunas de las hipotesis de la llamada teoría de la dependencia, si bien en una de sus versiones más débiles: ver Ludema, Rodney D. (2001) “The return of dependency Theory: Is primary commodity specialization bad for development?', en International Economic Review, Sept.Oct. (US.S. International Trade Commission Publication 3466).

IMF, World Economic Outlook. Washington: International Monetary Fund. Mayo, 1997, p. 78. 
correlación, además con el tamaño absoluto del mercado (la población), con diversos indicadores de desarrollo como el producto nacional bruto y la urbanización, así como con otras variables referidas al desarrollo de otras industrias culturales, tanto en términos de posibilidades de producción como de recepción. ${ }^{36}$ Por ejemplo, los grandes productores cinematográficos (más de 200 filmes al año) registraban un índice de desarrollo humano promedio (IDH, elaborado por la ONU) de 0.807 ; los medianos productores presentaban un promedio de 0.786 del mismo índice, mientras que los pequeños y nulos productores tenían 0.717 y 0.581 respectivamente. A pesar de que China (incluyendo a Hong Kong), India y Filipinas, se encuentran entre los mayores productores de filmes del mundo, Estados Unidos da cuenta de $85 \%$ del comercio mundial cinematográfico registrado en tal encuesta.

Según el Informe Mundial de Cultura de la UNESCO de 2001, en 1998 los países industrializados publicaban 218 periódicos diarios por cada mil personas, mientras que las naciones en desarrollo tiraban 40 (el promedio mundial era de 78 diarios por mil personas). ${ }^{38}$ De acuerdo con otro informe, la mitad de los países del mundo produce anualmente, en promedio, menos de un libro por habitante; $30 \%$ genera entre uno y tres libros, mientras que $20 \%$ elabora cuatro o más libros por persona. ${ }^{39}$ Alrededor de $60 \%$ de los países poseen menos de 50 copias de libros de texto por cada mil habitantes, mientras que en un $20 \%$ hay en promedio más de un libro de texto por cada habitante. ${ }^{40}$ Las desigualdades existentes en el orden mundial afectan producen a su vez intercambios inequitativos. En términos del comercio mundial de impresos, las proporciones que intercambian países ricos y pobres se presentan en la Gráfica 1. En la Gráfica 2 se aprecia el comercio exterior conjunto de libros, de los países del TLCAN.

${ }^{36}$ UNESCO, A Survey on National Cinematography. París, 2000

(http://mirror-us.unesco.org/culture/industries/cinema/html_eng/survey).

${ }^{37}$ ibid.

${ }^{38}$ UNESCO, Informe Mundial sobre la Cultura 2000-2001. Diversidad cultural, conflicto y pluralismo. París/Madrid: Ediciones UNESCO/Ediciones Mundo-Prensa, 2001.

${ }^{39}$ UNESCO, Facts and Figures 2000. París: UNESCO Institute for Statistics, 2000 p. 33..

Íbidem. 


\section{Gráfica 1}

Comercio mundial de impresos, 1998

(.000 U.S.)

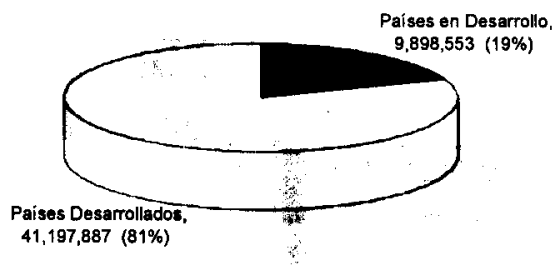

Fuente: UNESCO (2000) International Flow of Selected Cultural Goods 1980-1998. París: UNESCO Institute for Statistics.

Gráfica 2

Comercio Exterior de libros, países del TLCAN (Años seleccionados)

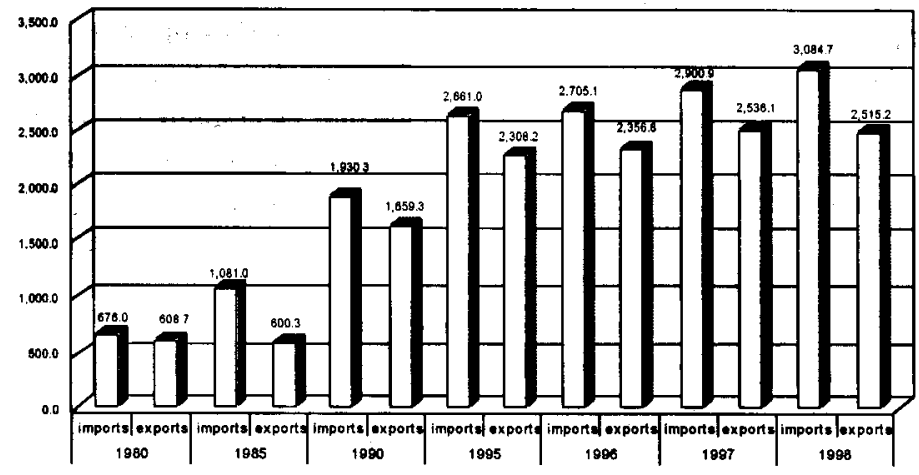

Fuente: UNESCO (2000) International Flow of Selected Cultural Goods 1980.1998. París: UNESCO Institute for Statistics.

Se puede advertir un déficit, no muy pronunciado, que en realidad producen los dos "socios menores" de esta agrupación internacional (Canadá y México), pues Estados Unidos es el principal exportador de impresos en el mundo. Enseguida veremos los intercambios entre estos tres países, pero antes nos interesa mostrar el gráfico similar al anterior, pero correspondiente al comercio exterior de libros de los países del Mercosur, donde se ve en contraste un déficit bastante mayor que el anterior. 
Gráfica 3

Mercosur, comercio exterior de libros

(Años seleccionados)

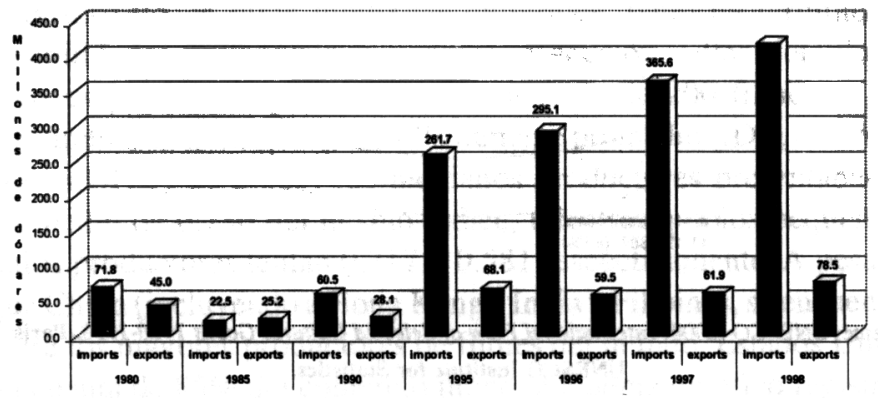

Fuente: UNESCO (2000) International Flow of Selected Cultural Goods 1980-1998. París: UNESCO Institute for Statistics.

Ahí está reflejada, seguramente, la enorme disminución de la producción y de las exportaciones de Argentina en los últimos años, por la terrible crisis que la asoló. El formidable déficit latinoamericano en la industria editorial se corrobora, finalmente, en la siguiente gráfica, correspondiente a ALADI, que incluye a más países de América Latina, entre ellos a México, Venezuela, Panamá, etc.

\section{Gráfica 4}

Comercio exterior de libros, ALADI

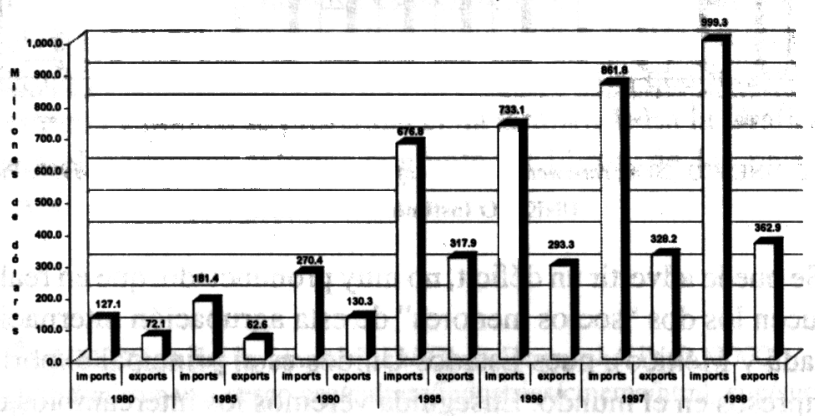

Fuente: UNESCO (2000) International Flow of Selected Cultural Goods 1980-1998. París: UNESCO Institute for Statistics.

El desglose por país muestra claramente las enormes disparidades en el comercio internacional de libros entre los países del norte y los del sur del Continente Americano.. 


\section{Cuadro 1}

América

Importaciones y exportaciones de productos editoriales

1995-2000

(Millones de dolares)

\begin{tabular}{|c|c|c|c|c|}
\hline \multirow{3}{*}{$\begin{array}{l}\text { Estados Unidos } \\
\text { Canadá }\end{array}$} & \multicolumn{2}{|c|}{$\begin{array}{c}1995 \\
\text { Importaciones Exportaciones }\end{array}$} & \multicolumn{2}{|c|}{2000} \\
\hline & 1,606 & 2,867 & 2,188 & 3,113 \\
\hline & 1,639 & 366 & 1,716 & 517 \\
\hline México & 272 & 117 & 496 & 163 \\
\hline Brasil & 236 & 22 & 205 & 18 \\
\hline Argentina & 103 & 87 & 182 & 77 \\
\hline Venezuela & 58 & 4 & 99 & 6 \\
\hline Colombia & 68 & 106 & 52 & 93 \\
\hline Chile & 57 & 112 & 50 & 65 \\
\hline Perú & 28 & 2 & 37 & 11 \\
\hline Guatemala & 15 & 1 & 28 & 2 \\
\hline Costa Rica & 21 & 8 & 27 & 7 \\
\hline Panamá & 19 & - & 25 & -- \\
\hline El Salvador & 11 & 2 & 22 & 1 \\
\hline Ecuador & 39 & 1 & 20 & 2 \\
\hline Honduras & 5 & -- & 11 & $\cdots$ \\
\hline Nicaragua & 5 & - & 9 & -- \\
\hline Paraguay & 5 & 1 & 8 & 1 \\
\hline Bolivia & 7 & - & 8 & - \\
\hline Uruguay & 1 & - & 2 & -- \\
\hline Jamaica & 17 & 1 & - & -- \\
\hline Trinidad Tobago & 9 & 2 & -- & -- \\
\hline Barbados & 6 & 1 & - & - \\
\hline Santa Lucia & 3 & -- & -- & -. \\
\hline Grenada & 2 & - & -- & -- \\
\hline Belice & 2 & -- & - & -- \\
\hline San Vicente & 1 & -- & -- & -. \\
\hline Saint Kitts Nevis & 1 & -- & -- & -- \\
\hline & 4,236 & 3,700 & 5,185 & 4,076 \\
\hline
\end{tabular}

Fuente: DATAINTAL, en Jaramillo, Bernardo (2002) «ALCA: Un desafio para las industrias culturales: La industria editorial ante la negociación del ALCA» Bogota: CERLALC, Informe de avance de Investigación

Esto simplemente es un recuento descriptivo con la información disponible, para imaginarnos qué va a pasar cuando por ejemplo el Acuerdo de Libre Comercio de las Américas entre en vigor, especialmente si se incluyen las industrias culturales, entre ellas la editorial, como si fueran zapatos o cualquier otra mercancía. 
Pero revisemos brevemente el caso de la industria editorial mexicana, que históricamente ha sido una de las de mayor fortaleza en América Latina.

\section{“Hacia un país de lectores”... ¿sin industria editorial?}

El programa de fomento a la lectura que puso en marcha el presidente Vicente Fox a mediados de 2002, fue llamado "Hacia un país de lectores". "Lo paradójico del caso es que al tiempo que se elaboraba este programa, el gobierno federal también elaboraba un proyecto para reducir los apoyos fiscales a la industria editorial, lo que causó risas irónicas, pero principalmente enojo en los sectores vinculados con la cultura, la educación y en general entre quienes aprecian los libros y la lectura en México. De hecho, el gobierno foxista llevaba ya por lo menos un año $_{43}$ "amenazando" con reducir los subsidios fiscales, ${ }^{43}$ pero tuvieron el mal tino político de anunciar ambos movimientos muy cercanamente en el tiempo. ${ }^{44}$ Afortunadamente, a fin de cuentas el gobierno rectificó las medidas tomadas y la industria no fue tan afectada como se temió. ${ }^{45}$ No obstante, hace falta mucho todavía para promover la publicación y la lectura de libros en nuestro país. La salud de la industria proveedora de la lectura de los mexicanos no se encuentra en su mejor estado, como se puede observar en el Cuadro 3.

41 "La SEP dedica 500 millones para fomentar la lectura", en Público, 14 de Marzo de 2002 (Secc. Cultura, P. 3).

42 "Golpeará a la industria editorial la eliminación del trato fiscal preferente", en El Financiero, 4 de junio, 2002, Pág. 8.

43 "Sería desastroso aplicar el IVA a libros: editores", La Jornada, 30 de marzo de 2001, Secc. Cultura, Pág. 4".

44 "Los esfuerzos por la lectura, a la basura", Público, 4 de junio de 2002, Secc. Cultura, Pág. 3.

45 "Decreto de la SHCP restituye beneficios a editoriales. Pendiente, el reglamento sobre la devolución del IVA", en El Financiero, 27 de junio de 2002, pág. 9. 
Cuadro 3

México: indicadores del sector editorial privado

\begin{tabular}{|c|r|r|r|}
\hline Variables & \multicolumn{1}{|c|}{1999} & \multicolumn{1}{|c|}{2000} & Variación $\%$ \\
\hline Núm Editores & 237 & 238 & -- \\
\hline Producción de títulos & 18,097 & 16,003 & -11.5 \\
\hline Producción ejemplares & $115,426,429$ & $97,805,581$ & -15.2 \\
\hline Títulos en coedición & 431 & 606 & 40,6 \\
\hline Ejemplares en coedición & $2,017,302$ & $3,018,374$ & 49.6 \\
\hline Títulos en catálogo & 127,484 & 132,109 & 3.6 \\
\hline Títulos vendidos & 101,374 & 111,691 & 10.1 \\
\hline Ejemplares vendidos & $115,239,303$ & $102,519,081$ & -1.1 \\
\hline Valor de venta & $\mathrm{nd}$ & $5,551,742,428$ & - \\
\hline Títulos exportados & 52,830 & 84,554 & 60 \\
\hline Exportación de ejemplares & $14,461,810$ & $10,210,540$ & -29.3 \\
\hline Títulos importados & 40,907 & 51,538 & 25.9 \\
\hline Importación de ejemplares & $17,928,139$ & $15,614,760$ & -12.9 \\
\hline Inversión publicitaria & $386,215,454$ & $283,091,318$ & -26.7 \\
\hline
\end{tabular}

nd = no disponible

Fuente: Caniem (2002) Actividad editorial 2000. Libros México:

CANIEM/CONACULTA/ CERLALC

En el cuadro se muestran algunos indicadores del sector editorial privado mexicano, en los años 1999 y 2000 , mismos que muestran una disminución en la producción tanto de títulos $(-11.5 \%)$ como de ejemplares $(-15.2 \%)$, así como un menor dinamismo en el comercio exterior, pues disminuyeron considerablemente las exportaciones y las importaciones de ejemplares. De hecho, esta tendencia comenzó a acentuarse desde la crisis de mediados del decenio pasado, pues según otro informe de la Cámara Nacional de la Industria Editorial Mexicana, el valor de la producción editorial pasó de 630 millones de pesos registrados en 1994 a 403 millones en 2000. Las ventas descendieron de 543 millones de pesos a 362 millones durante el mismo período. ${ }^{46}$ El sector editorial mexicano ha estado, en los últimos

${ }^{46}$ Audifred, Myriam (2002) "Los libros al alza ... de precios", en Público, 9 de enero, Secc. Cultura, Pág. 7. 
años, disminuyendo su producción y su presencia internacional. " $\mathrm{La}$ desfavorable evolución de la producción y las ventas incidió en una reducción importante del número de editores, pues de 423 existentes en 1991 sólo se contabilizaron 237 en 1999". Si se considera que en 1991 se produjeron 21,500 títulos, y para el 2001 esta cifra fue ya solamente de 15,937 , se tiene una idea de que estamos hablando prácticamente de una "década perdida para la industria editorial en México"

La situación para editores y libreros empeora si se tiene en cuenta la "contribución" de la piratería y el fotocopiado, pues se calcula que "México ocupa el tercer lugar mundial en el fotocopiado, producción y comercialización de productos editoriales piratas", lo que "representa un daño económico anual de mil 250 millones de pesos para los libreros y 950 millones de pesos para los editores". En la medida en que se ha ido reduciendo la producción y el mercado de libros en México, han desaparecido las empresas. Así, mientras que oficialmente (tanto por parte del gobierno como de la Cámara respectiva) se considera que hay alrededor de 400 librerías en el país, una investigación del Grupo Noriega Editores arroja que en realidad existen 366 establecimientos donde se venden libros, de los cuales solamente 151 pueden clasificarse estrictamente como librerías. ${ }^{49}$ Es verdaderamente alarmante este dato y significa que la producción y el comercio de libros necesitan mucho más que "fuerzas del mercado" para volver a crecer y posicionarse como un sector económicamente sano de las industrias culturales.

Con respecto al sector externo, en el siguiente gráfico mostramos la evolución reciente de los intercambios internacionales de México.

${ }^{47}$ Ibid.

48 "Una década perdida para la industria editorial en México", en Público, 26 de febrero de 2003, Secc. Cultura, Pág. 44.

49 "El dato oficial es ficticio: en México sólo existen 151 librerías", en $E l$ Financiero, 22 de agosto de 2003, Pág. 54. 


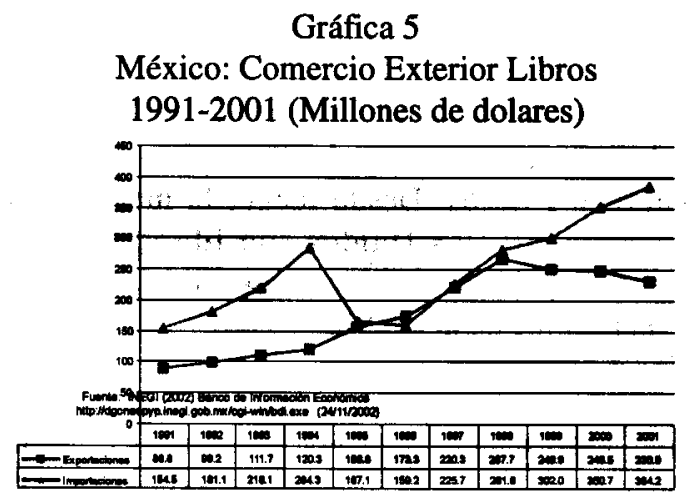

Fuente: INEGI (2002) Banco de Información Económica

http://dgcnespyp.inegi.gob.mx/cgi-win/bdi.exe (24/11/2002)

Se nota claramente que, a raíz de la crisis de fines de 1995 , hubo una disminución enorme en las importaciones; después crecieron juntas importaciones y exportaciones por unos tres años y luego se separaron, y otra vez México es un importador neto de libros. Más ampliamente, la rama del papel, imprentas y editoriales ha continuado siendo deficitaria frente al exterior.

Gráfica 6

Comercio exterior entre México y Estados Unidos

1992-200

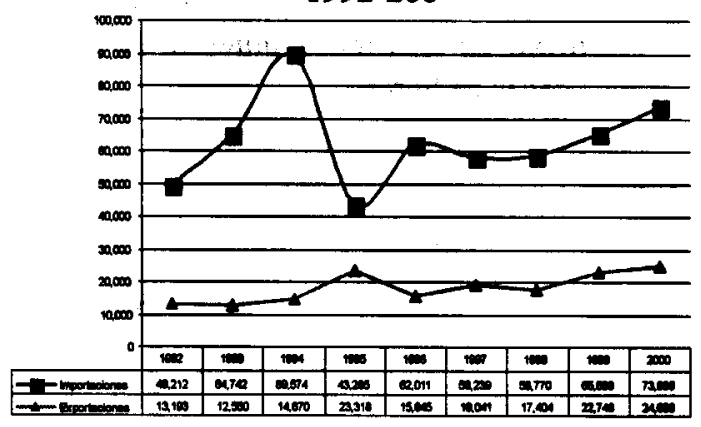

Fuente: Departamento de Comercio de E.U. http:/www.ita.doc.gov/td/ocg/archive/aexp2731.htm y http://www.ita.doc.gov/td/ocg/archive/aimp2731.htm

(Bajados el 27/11/2002)

${ }^{50}$ "Crece $9.2 \%$ el déficit comercial en la industria del papel y editoriales; acumula 1,423 mmd a mayo", en El Financiero, 16 de julio 2003, Pag. 14. 
En el gráfico 6 se representa el comercio de libros entre México y Estados Unidos. Es, también clara la reducción de los intercambios a raíz de la crisis en 1995, y después nuevamente el crecimiento de las importaciones de nuestro socio del TLCAN, que es el país al que más le compramos libros. Desde luego, la mayor parte de las importaciones de Estados Unidos son libros necesariamente traducidos, pues la población mexicana no lee mayoritariamente en inglés. Dice el informe de la CANIEM:

Durante el año 2000, los editores de libros del sector privado publicaron 1,784 títulos que fueron escritos originalmente en otros idiomas y traducidos al español, mientras que sólo 33 títulos originalmente escritos en español y editados en México fueron cedidos para traducción a otros idiomas en el extranjero.

De lo anterior resulta que por cada título mexicano traducido a otros idiomas, hubo 54 títulos extranjeros traducidos en México, por lo que la balanza de comercio intelectual con otras lenguas continúa siendo muy negativa. ${ }^{51}$

Ahora bien, añade el informe que más del $90 \%$ del total de traducciones, tanto en títulos como en ejemplares, provienen del inglés, al que muy de lejos le siguen el francés y el portugués.

Después de Estados Unidos, nuestro siguiente proveedor de libros es España, del cual somos a la vez el primer país comprador, pues en los últimos años México sustituyó a Argentina como su principal cliente en el sector editorial. El Gráfico 7 muestra el origen de las importaciones mexicanas de libros. 


\section{Gráfico 7}

México: Distribución porcentual de la importación de ejemplares de libros por países, 1999

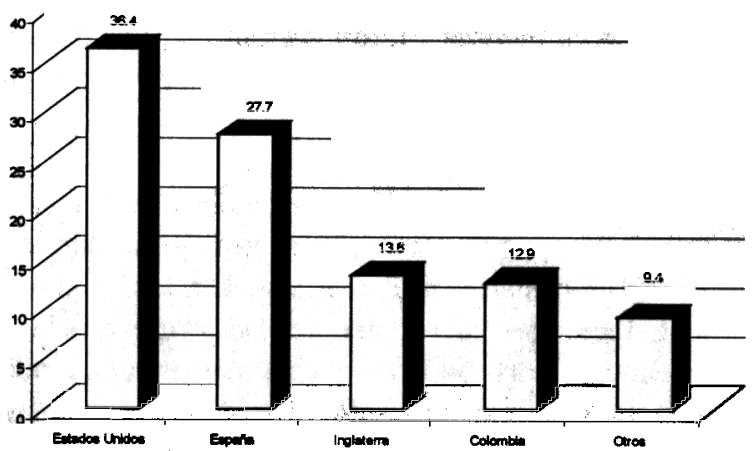

Fuente: INEGI (2002) Estadisticas de Cultura. Edicion 2001.

México: Instituto Nacional de Estadística, Geografía e Informática.Gráfica 25

Los destinos de las exportaciones mexicanas, por otro lado, se muestran en el Gráfico 8.

\section{Gráfico 8}

Distribución porcentual de la exportación de ejemplares de libros por países, 1999

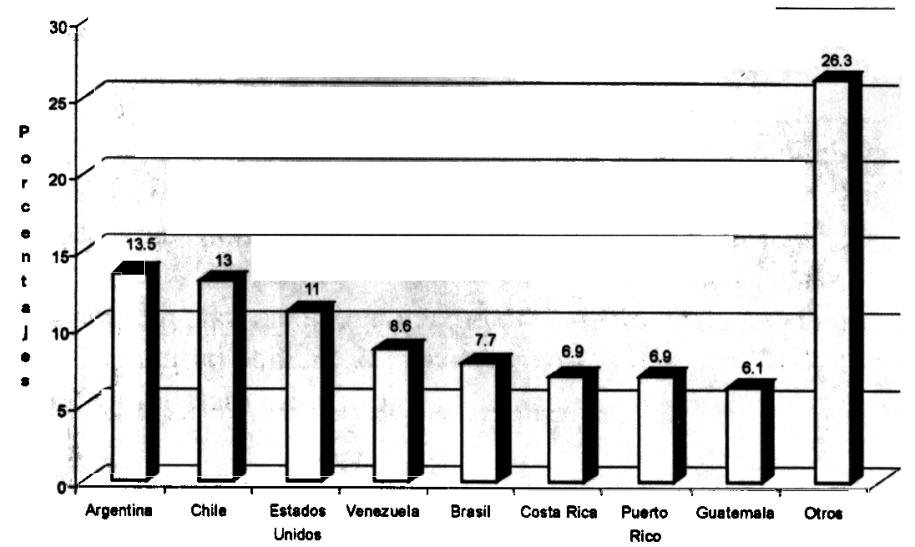

Fuente: INEGI (2002) Estadísticas de Cultura. Edición 2001.

México: Instituto Nacional de Estadística, Geograffa e Informática.Gráfica 25 
Los principales compradores son Argentina, Chile, Estados Unidos. España no alcanza a aparecer en la gráfica, puesto que contribuye con un porcentaje muy pequeño. De Estados Unidos, somos el quinto lugar como destino de sus libros exportados, mientras que en términos de sus fuentes de importación, ocupamos el lugar número 13 . $^{52}$ Sin embargo, en términos más amplios de la industria de la edición y la imprenta, México es ya el segundo mercado de Estados Unidos, tanto de importaciones como de exportaciones.

\section{COLOFÓN}

Vemos entonces que el comercio internacional de libros de México está altamente concentrado (como casi todo el comercio exterior mexicano), con un principal socio, Estados Unidos, y un número relativamente reducido de "socios menores". Sin embargo, la presencia española está incrementándose, tanto en términos comerciales, como de inversión extranjera directa.

A la crisis descrita tambien en líneas anteriores, habría que añadir el proceso de concentración y de transnacionalización de la industria editorial mexicana. Recordemos que las grandes editoriales españolas son parte de grupos más grandes con sede en otros países, como la transnacional alemana Bertelsman. Se necesitan acciones y políticas públicas con visión de Estado al interior de México, así como acciones conjuntas a nivel latinoamericano, para impulsar la producción y la distribución/comercialización de libros.

1. Se requiere dar estímulos fiscales, subsidios y otros apoyos a los editores.

2. El gobierno debe pasar a los editores privados la producción de los libros de texto de primaria.

3. La distribución y la comercialización de libros y revistas también deben recibir apoyos fiscales y directos, porque la distribución es un cuello de botella usual y la venta final al público es la interfase clave para la eventual realización de estas mercancías simbolicas.

4. Con respecto al comercio internacional, no se trata de "cerrar fronteras". De lo que se trata es de, por un lado buscar que nuestros intercambios sean menos desiguales (deficitarios). Por

52 En http://www.ita.doc.gov/td/ocg/archive/aexp2731.htm; y http:// www,ita.doc.gov/td/ocg/archive/aimp2731.htm, 27/11/2002.

"U.S.-Mexico Printing/Publishing Industry", en Trade Commision of Mexico Newsletter, Junio de 2001 (Bancomext, Trade Commission of Mexico in Los Angeles; http://www.mexico-trade.com/JUNE01/page2.html, 27/1 1/2002). 
otro lado, se debe intentar diversificar las fuentes de las importaciones, como en prácticamente todas las ramas de las industrias culturales, donde predomina un solo país.

Pero por sobre todas las medidas, se requiere seguir impulsando la lectura, a través de la educación formal, tanto como a través de mecanismos de educación no formal e informal, como los medios de difusión.

El libro no es solamente y simplemente una mercancía: Es un vehículo mediante el cual las sociedades se sueñan, se recuerdan y recrean, se registran y se imaginan, se encuentran y reencuentran. La palabra impresa es portadora de pensamiento, concepto, sueño, conocimiento, inspiración, imaginación. Es cultivo y cultura en el más alto y mejor sentido de la palabra. No es la "oferta y la demanda" (controladas en el capitalismo global por las grandes corporaciones) las que van a fomentar el desarrollo de industrias culturales tan importantes para el espíritu humano, como la editorial 